\title{
Entre Contact Zones y Safe Houses: las comunidades étnicas ante el estado-nación argentino
}

\author{
Between Contact Zones and Safe Houses: ethnic communities before the \\ Argentine nation-state
}

\author{
Tomás Schierenbeck \\ t_schierenbeck@hotmail.com \\ CONICET - Instituto de Investigaciones en \\ Humanidades y Ciencias Sociales - Universidad \\ Nacional de La Plata, Argentina
}

Recepción: 17 Septiembre 2020

Aprobación: 25 Noviembre 2020

Publicación: 04 Enero 2021

Cita sugerida: Schierenbeck, T. (2021). Entre Contact Zones y Safe Houses: las comunidades étnicas ante el estado-nación argentino. Trabajos y Comunicaciones, (53), e135. https://doi.org/10.24215/23468971e135

\begin{abstract}
Resumen: Proponemos adaptar los conceptos formulados por Pratt (1991) en Arts of the Contact Zone como herramientas teóricas capaces de analizar las estrategias desplegadas por distintos colectivos étnicos asentados en la ciudad de Buenos Aires entre fines del siglo XIX y principios del XX para acomodarse a las coyunturas políticas de la sociedad porteña. Para esto, exhibiremos, mediante los proyectos educativos de distintas escuelas bilingües y las acciones de la colectividad alemana en la ciudad durante la Gran Guerra, como estas desarrollaron "espacios seguros" donde resignificaban su identidad colectiva sin desvincularse del Estado-nación argentino ni ocultando su componente étnico.
\end{abstract}

Palabras clave: Buenos Aires, Contact Zone, Safe House, Colectividades étnicas.

Abstract: We propose to adapt concepts suggested by Pratt (1991) in Arts of the Contact Zone into theoretical tools capable of revealing how those ethnic groups settled in Buenos Aires between the end of the 19th century and the beginning of the 20th deployed different strategies in order to accommodate themselves to particular political climates in the local society. For this, we will show, through the educational projects of different bilingual schools, as well as in the actions of the German community in the city during the Great War, how they developed "safe spaces" where they redefined their collective identity, all without dissociating themselves from the Argentine nation-state or hiding its ethnic component.

Keywords: Buenos Aires, Contact Zone, Safe House, Ethnic collectives.

\section{INTRODUCCIÓN:}

Entre 1880 y 1914 la Argentina recibió más de 4 millones de emigrados provenientes de distintos puntos del globo (Devoto, 2003). Ciudadanos italianos, españoles, alemanes, otomanos, entre otros, arribaron a las costas del Rio de la Plata con diversos objetivos, asentándose en su mayoría en la Capital Federal y en los conglomerados urbanos de las provincias de Buenos Aires, Córdoba y Santa Fe (Bjerg, 2009). Aquellos migrantes, que en su mayoría provenían de zonas rurales del sur de Europa, se sintieron atraídos por las oportunidades laborales que la Argentina proveía ante el avance de su frontera agrícola como por las distintas 
obras de infraestructura, de carácter público como privado, que aseguraban a sus potenciales empleados un puesto de trabajo seguro por un prolongado periodo de tiempo (Devoto, 2003). Con el correr de los años, los emigrados y sus familias fueron organizándose en distintos colectivos étnicamente definidos (las denominadas colectividades) donde, mediante una serie de prácticas culturales como espacios comunes, desarrollaron una sociabilidad cargada de representaciones sobre un pasado y presente compartido que les permitían sentirse acompañados y, a la vez, posicionarse ante las distintas circunstancias imperantes tanto en su lugar de origen como en su nueva patria.

A pesar que dentro de la historiografía nacional las experiencias de distintos colectivos fueron objeto de indagación de una gran cantidad de investigaciones de índole tanto cuantitativo como cualitativo, reconocemos cierta vacancia a la hora de conceptualizar los procesos de choque, recepción e intercambio cultural de grupos e individuos que integraban las distintas colectividades en su sociedad de acogida dentro del análisis histórico ${ }^{1}$. En este sentido, el siguiente artículo se propone adaptar los conceptos desarrollados en Arts of the Contact Zone por Mary Louise Pratt (1991) como artefactos teóricos capaces de generar una mayor aproximación a las experiencias de las colectividades étnicamente definidas en su relación con la sociedad en la que se establecieron. Se comprende así que los estímulos de la sociedad y cultura predominante son apropiados y redimensionados en los "espacios seguros" o safe houses de cada colectivo, para ser nuevamente transmitidos desde allí hacia la esfera pública en narrativas, proyectos e interpretaciones de la realidad de carácter alternativo respecto a los hegemónicos en la sociedad imperante. En un sentido análogo, estos conceptos han sido apropiados en distintas disciplinas como la antropología y la literatura como herramientas válidas para evidenciar espacios y prácticas que se desarrollan en contextos de diversidad cultural (Golluscio \& Dreidemie, 2017; D'Amore, 2010; Colera, 2008; Merry, 1998).

El siguiente artículo se estructura en tres partes. Primero, un sucinto análisis de la obra de Pratt (1991) donde se definen los conceptos contact zone y safe house. Segundo, una breve caracterización de los espacios de sociabilidad que las comunidades étnicas desarrollaron en la ciudad de Buenos Aires y su interpretación como espacios seguros (safe houses). Por último, y a modo de exponer la practicidad de estos conceptos, nos proponemos recuperar algunas obras referidas a las escuelas bilingües en la ciudad de Buenos Aires a fines del siglo XIX y principios del XX. En tanto, como ha propuesto Bryce (2019), los proyectos de aquellas comunidades educativas no solo se desarrollaron en una constante negociación por respetar los requerimientos establecidos por el Consejo Nacional de Educación, sino también estimularon una significación distinta de ciudadanía respecto a la promovida por el Estado argentino en las escuelas públicas. También daremos cuenta de cómo la colectividad alemana durante la Gran Guerra (1914-1918) estableció diferentes estrategias para respaldar su lugar en la sociedad argentina ante un contexto contrario.

\section{Planteamientos básicos sobre el tema:}

En el año 1991 fue publicado en la Modern Language Association of America (MLA) el breve artículo Arts of the Contact Zone. En él, Mary Louise Pratt definió aquellos espacios donde las culturas y las identidades interactúan como contact zones. Es decir, "social spaces where cultures meet, clash, and grapple with each other, often in contexts of highly asymmetrical relations of power" (Pratt, 1991, p.34). A modo de dar cuenta de la operatividad de este concepto, la autora analizo las crónicas de Felipe Guamán Poma de Ayala tituladas Primer nueva crónica y buen gobierno (1615) y las experiencias de sus propios hijos (Sam y Manuel) como ejemplos de sujetos que, a pesar de las circunstancias históricas de cada caso, compartían la característica de estar alcanzados simultáneamente por dos culturas, viéndose en la necesidad de resistir y/o constantemente negociar por inhibir su asimilación a una única identidad cultural dominante (Elmborg, 2006).

En el caso de Sam, Pratt (1991) nos advierte que cuando este juega con sus cartas de Beisball, donde se mencionan nombres de jugadores de diferente origen (japonés, español, polaco, etc.), y este intenta pronunciarlos de modo correcto sin tener conocimiento de aquellas lenguas, se encuentra decodificando 
mediante una negociación entre su lengua materna con aquellos idiomas. Al mismo tiempo, cuando su hijo Manuel desarrolla una forma curiosa (entre parodia y fantástica) de resolver las tareas indicadas por su maestra sin que aquella astucia sea reconocida por la autoridad en el aula -para caer luego en la indiferencia de la relación Maestra-Alumno, para Pratt el joven inconscientemente se encontraba enfrentándose a la estructura y dinámica de una cultura predominante en el aula. Asimismo, en aquellas crónicas redactadas en una narrativa bilingüe (quechua y español) y a modo de carta hacia el rey Felipe III de España, Guamán Poma desarrollo su interpretación de la Historia del mundo andino bajo los parámetros coloniales en los que se encontraba:

Poma begins by rewriting the Christian history of the world from Adam and Eve, incorporating the Amerindians into it as offspring of one of the sons of Noah. He identifies five ages of Christian history that he links in parallel with the five ages of canonical Andean history separate but equal trajectories that diverge with Noah and reintersect not with Columbus but with Saint Bartholomew, claimed to have preceded Columbus in the Americas (Pratt, 1991, p.34).

Este análisis era acompañado por una descripción de las costumbres, leyes y formas de organización vigentes en el Tahuantinsuyo, y de una propuesta personal para desarrollar una nueva dirección en el gobierno colonial del Cuzco (Pratt, 1991). Sosteniendo los cuantiosos beneficios de establecer una administración versada en las históricas estructuras sociales andinas, en interacción con la fe cristiana y la tecnología colonial,

The epistle ends with an imaginary question-and answer session in which, in a reversal of hierarchy, the king is depicted asking Guaman Poma questions about how to reform the empire? a dialogue imagined across them any lines that divide the Andean scribe from the imperial monarch, and in which the subordinated subject single-handedly gives himself. (Pratt, 1991, p.36).

Este estilo de narrativa fue definido por Pratt (1991) como "an autoethnographic text, by which I mean a text in which people undertake to describe themselves in ways that engage with representations others have made of them" (p.35). En tanto, la forma de escritura como las ideas desarrolladas en las crónicas donde se observa una apropiación de prácticas y costumbres culturales coloniales (el cristianismo, la escritura y el lenguaje) es identificado por la autora como un claro ejemplo de transculturalidad, Es decir, "processes whereby members of subordinated or marginalized groups select and invent from materials transmitted by a dominant or metropolitan culture" (p.36). Sin embargo, la historia de las crónicas analizadas marca que jamás llegaron a su destinario, sino que permanecieron en la Biblioteca Real de Copenhague hasta 1909 cuando el bibliotecario Richard Pietschmann las redescubrió y logro años más tarde presentar su análisis de las mismas al circuito académico en 1912.

En este sentido, Pratt (1991) indica tanto el destino de la magnífica obra de más de 1000 páginas y 300 grabados de Guamán Poma, como de la astuta respuesta de su hijo hacia una tarea, son un claro producto de la literatura en la contact zone (o zonas de contacto) caracterizada por registros de "autoethnography, transculturation critique, collaboration, bilingualism, mediation, parody denunciation, imaginary dialogue, vernacular expression" (p.37). Una serie de operaciones narrativas donde se producen "miscomprehesion, incomprehension, dead letters, unread masterpieces absolut heterogeneity of meaning" - these are some of perils of writing in the contact zone" (p.37).

En esta sintonía, los ejemplos de Guamán Poma y el pequeño Sam en los que nos hemos detenido hasta aquí fueron utilizados para analizar y caracterizar el sistema académico y el aprendizaje en las aulas a sabiendas de comprender que estas últimas, en lugar de funcionar como un espacio homogéneo o un espacio horizontal entre sus integrantes, lo hacen a modo de una zona de contacto. Donde "[e]very single text we read stood in specific historical relationships to the students in the class, but the range and variety of historical relationships in play were enormous" (Pratt, 1991, p.39). Esto sucede para Pratt en la medida en que la comunidad académica parte de la base de que todos sus integrantes se comprenden de unos mismos código, saberes y normas previas aprehendidas, los que hacen que "whatever conflict or systematic social differences might be in play, it is assumed that all participants are engaged in the same game and that the game is the same for 
all players" (p.38). Generando a su vez que, en una misma aula donde comparten espacio distintos sujetos con diferentes trayectorias de vida, algunos jóvenes tengan una relación conflictiva con las instituciones y programas educativos ante un comportamiento y "lectura" distintita de la "apropiada" en el marco educativo (Elmborg, 2003; Canagaraja, 1997; Pratt, 1991).

Sin embargo, estos espacios donde los individuos se encuentran bajo stress y vivencian dolor e indiferencia ante una cultura dominante que inhibe la legitimidad de sus saberes se ven acompañados también por experiencias enriquecedoras en el dialogo intercultural que se generan en la misma. En términos de Pratt (1991), "moments of wonder and revelation, mutual understanding, and new wisdom" (p.39), así como por distintas estrategias y ámbitos que permiten a los sujetos resistir aquellas experiencias apáticas. Estos últimos, la autora nos propone comprenderlos como "safe house", definidas como "social and intellectual spaces where groups can constitute themselves as horizontal, homogeneous, sovereign communities with high degrees of trust, shared understandings, and temporary protection from legacies of oppression" (p.40). Espacios que funcionan para grupos marginados o minoritarios como, "safe houses in which to construct shared understandings, knowledges, claims on the world that they can then bring into the contact zone" (p.587). En este sentido, Pratt culmina su artículo postulando la necesidad de desarrollar una "curricula multicultural" de modo que todos los grupos puedan sentirse en algún momento reconocidos dentro del sistema.

A partir de esta publicación una serie de autores supieron implementar y rediseñar las categorías de safe house y conctact zone como conceptos teóricos que les permitían dar cuenta de las experiencias y estrategias que distintos alumnos desarrollaron en sus aulas. Por ejemplo, en cursos de enseñanza de una segunda lengua extranjera o introductorios en la escritura académica, para sobrellevar las diferencias establecidas entre sus experiencias individuales y/o colectivas acumuladas y la cultura académica de las instituciones en las que participaban (Pomerantz, \& Bell, 2011; Canagarajah, 1997; Lu, 1994). Asimismo, los postulados de Pratt (1991) también han conllevado a estimular propuestas para reformular espacios académicos como, por ejemplo, las bibliotecas, entendidas por Elmborg (2006) como zonas de contacto. Este último postuló establecer un mayor acercamiento entre los estudiantes y el personal bibliotecario, donde los profesionales puedan encontrar su "identidad pedagógica" en la medida que generen una mayor proximidad entre los jóvenes y los sistemas informáticos, su lenguaje y técnicas de búsqueda.

El trabajo de Pratt tampoco estuvo ajeno a críticas u observaciones que llamaron a la cautela respecto a la factibilidad de concebir a las aulas simplemente como zonas de contactodondelos jóvenes enfrentan conflictivamente la diferencia con sus pares y la comunidad académica (Harris, 1995). Del mismo modo que, Watkins (2003) mediante un análisis de los estudios de Gloria Anzaldura (1999) y la cultura chicana, también advirtió reconocer que no siempre a cada zona de contacto se le puede adjudicar un espacio seguro donde los grupos minoritarios pueden sentirse a salvo y legitimados.

Mediante un repaso de algunas investigaciones en el campo, en el siguiente apartado nos detendremos analizar los espacios étnicos que distintas colectividades desarrollaron en la Ciudad de Buenos Aires, en tanto comprendemos que la relación que estas entablaron con el Estado y la sociedad argentina puede ser analizada y comprendida en los términos anteriormente expuestos.

\section{ESPACIOS DE SOCIABILIDAD DE LAS COLECTIVIDADES ÉTNICAS A INICIOS DEL SIGLO XX:}

A través del mecanismo de migración en "cadena” como mediante los proyectos de colonización agrícola estimulados por el Estado argentino entre mediados del siglo XIX y principios del XX, la Argentina se constituyó como uno de los países con mayor tasa de inmigración a nivel global, registrando entre 1881 y 1914 aproximadamente 4.200 .000 arribos (Devoto, 2003). A pesar de ser en su mayoría hombres jóvenes, con baja calificación y de origen rural, los arribados se caracterizaron por asentarse en su gran mayoría en zonas urbanizados a punto tal que "en las ciudades y los pueblos residía el 74\% de los españoles, el 69\% de los italianos, el 73\% de los 'turcos'2 y el 57\% de los 'rusos"' (Bjerg, 2009, p.28). Aquellos migrantes 
que se asentaron en las regiones urbanas, principalmente en la metrópoli de Buenos Aires, participaron de una "sociabilidad cargada de significados étnicos" (p.35). Por ello se comprende "la tendencia de los seres humanos a interactuar con otros. Lo que hace posible la existencia de la sociedad", donde, dependiendo cada sociedad, existente "diferentes modelos de sociabilidad y uno de estos modelos es la creación de organizaciones (familias, grupo de amigos, clubes, asociaciones, etc.)". Pero, principalmente, como "un terreno de juego donde se produce la circulación y apropiación de "capital social y político" (prestigio, liderazgo, influencia, alianzas) mediante la utilización de determinadas estrategias por parte de los grupos e individuos" (Mangold, 2017, p.102).

En este sentido, las colectividades étnicas en la ciudad de Buenos Aires del entre siglos XIX-XX han sido analizadas a sabiendas de las estructuras organizacionales y problemáticas de sus integrantes y entidades, así como también de sus formas de participación (de modo formal e informal) en los debates nacionales e internacionales del momento (Bindernagel, 2017; Mcgee Deutsch, 2017; Tato, 2017; Cibotti, 2000). Sin embargo, y a pesar de las diferencias numéricas como políticas y culturales que acercaron o distanciaron a estas comunidades entre sí, o bien las condujeron a ser aclamadas y desprestigiadas por la sociedad porteña general, podemos advertir que en términos generales compartieron una serie de patrones de sociabilidad. Estos mismos habilitaron la generación, pervivencia y reproducción de sentidos de pertenencia (materiales o imaginados) que los unía como colectivo (étnico) que compartía ciertas prácticas religiosas, lingüísticas y/ o un pasado en común en la nueva metrópolis; o bien su autopercepción como diáspora ${ }^{3}$ de una sociedad distante en lo material que por diversas razones había recabado en las costas del Rio de la Plata, pero que continuaba comprometida en interceder y hacer pervivir el contacto con su sociedad de origen.

Dos de los principales espacios que tradicionalmente se suelen resaltar como vehículos de sociabilidad son las sociedades mutuales y los periódicos étnicos que circularon a gran escala entre fines del siglo XIX e inicios del XX. Respecto a las primeras, como bien ha planteado Bjerg (2009), el "grueso de estas entidades tenía por fin ocuparse de la salud de sus socios, de la ayuda para conseguir empleo y eventualmente del pago de seguros de desempleo o de repatriación para compaisanos indigentes" (p.46). Sin embargo, como bien han expuesto las investigaciones de Fernandez (1987) y Torry (2010) sobre el asocianismo español y vasco en Buenos Aires o bien, Newton (1977) y Otero (2010) respecto a las alemanas y francesas respectivamente, estos puntos también funcionaron como espacios de solidaridad y de reconocimiento mutuo entre sus integrantes donde, a pesar de las diferencias entre quienes se posicionaban como líderes y socios, el intercambio de narrativas entre experiencias y expectativas "contribuían a la creación de una identidad basada en representaciones que unían el pasado con el presente, a cuya dinámica se integraba de forma tenaz y costosa los inmigrantes" (Bjerg, 2009, p.48). En este mismo sentido, las obras de Fernandez (2001), De Cristóforis (2016) y Da Orden (2020) respecto a la comunidad gallega no solo han dado cuenta de la labor asistencial del Centro Gallego de la ciudad de Buenos Aires para la misma, sino también han marcado elementos interesantes como la composición de sus socios y las tramas dirigenciales en torno a los avatares de la política tanto nacional como europea. En un sentido análogo, Devoto (1987), Baily \& Scarli (1982) y Cibotti (2000; 1994) han expuesto la importancia de las entidades mutuales italianas y sus líderes en la esfera pública porteña como las pugnas entre los distintos representantes de los espacios étnicos.

La surtida variedad de periódicos étnicos publicados en las décadas de entresiglos también nos permiten dar cuenta del valor inconfundible que tuvo su producción y consumo "como parte de las prácticas culturales que marcaban y delimitaban identidades" en tanto "influía sobre la creación de una comunidad imaginada de la que sus lectores se sentían parte y en la que se entrelazaban las realidades políticas, sociales y económicas de la vieja patria y del nuevo país" (Bjerg, 2009, p.48). Además, como bien ha marcado Cibotti (2000) respecto a la comunidad italiana porteña, no debemos dejar de tener en cuenta que la prensa étnica funcionó como una vía (in)formal desde donde estos colectivos migrantes pudieron expresar su posicionamiento y convocar a movilizaciones de sus paisanos frente a los vaivenes de la política nacional y la imposibilidad de ejercer su 
derecho al voto. En este sentido, los datos expuestos por Gruss (2017) en su tesis de maestría no hacen más que afirmar la importancia de la práctica de la lectura entre los distintos grupos étnicos:

\begin{abstract}
En 1887, de las publicaciones periódicas en la ciudad de Buenos Aires, 82 estaban redactadas en español, 7 en italiano, 4 en inglés y también 4 en alemán. Del total de periódicos publicados en 1895 en el país, 255 eran de propietarios argentinos y 90 extranjeros, de los cuales 19 eran redactados en italiano, 9 en francés, 7 en inglés, 4 en alemán 1 en dinamarqués y el resto en castellano. Según el Censo Nacional de Población de 1914, entre las publicaciones periódicas existentes por entonces en la Argentina había 5 en inglés, igual cantidad en alemán, 4 en italiano, 3 en árabe, 2 en francés, 1 en dinamarqués, además de 7 publicaciones escritas en más de un idioma. (Gruss, 2017, p.97).
\end{abstract}

En este sentido, es concerniente al menos mencionar algunas investigaciones dentro de este campo. Por ejemplo, Garabedian (2012) ha indagado sobre la empresa El correo español del mismo modo que Garcia Sabastini (2004) ha estudiado el periódico El Diario español y Cagiao Vila (2002) ha hecho lo propio respecto a la prensa gallega en Buenos Aires durante la década del veinte de la centuria pasada. El rol de los periódicos de la comunidad italiana tanto como actores en la esfera pública porteña o bien como espacios de sociabilidad comunal también han sido un espacio de sucesivas investigaciones (Lobato, 2001; Dore, 2000; Cibotti, 1994; Baily, 1978). Empero no pocos avances se han desarrollado en torno a los medios gráficos de comunidades minoritarias como la germano parlante (Bindernagel, 2017; Bryce, 2009; Hoffman, 2009; Meding, 1995) o bien, la comunidad Idish e israelí en Buenos Aires (Dujovne, 2014; Shirp, 2001)

Otras instituciones y puntos que funcionaron como espacios de sociabilidad fueron las entidades religiosas y las escuelas formadas por las propias comunidades étnicas en la región. Como bien han desarrollado Bryce (2019) y Seiguer (2017), las iglesias luterana y anglicana que supieron asentarse en la región no solo permitieron la continuidad del culto para los emigrados, sino que también motorizaron una significación propia de lo que simbolizaba el "ser nacional" en el extranjero mediante un dialogo constante que conectaba la fe con las experiencias y esperanzas compartidas de sus fieles en la Argentina. Asimismo, sucesivas investigaciones también han expuesto las polémicas que a fines del siglo XIX se desarrollaron respecto al rol que cumplían las escuelas étnicas en la escena nacional (Bryce, 2019; Mcgee Deutsch, 2017; Seiguer; 2017; Otero, 2011; Cibotti, 2000). Si el objetivo principal era generar las posibilidades de que los hijos de la colectividad se formaran en un entorno que permitiera no perder la conexión con la cultura de sus padres, al mismo tiempo que formara a jóvenes preparados para vivir en la Argentina, tanto antes como tras la promulgación de la ley 1.420 de educación común no fueron pocos los momentos donde se polemizó respecto a qué tipo de ciudadanía se estimulaba dentro de aquellas instituciones educativas, a pesar del valor inconfundible que cumplieron en suplir las falta de infraestructura y plazas en el sistema educativo nacional de la época (Bryce, 2019; Seiguer, 2017; Cibotti, 2000).

En última instancia, las experiencias barriales y habitacionales también cumplieron su rol en la sociabilidad como en la multiplicidad identitaria de Buenos Aires (Bjerg, 2009). Tan solo para exponer algunos ejemplos, podemos indicar las investigaciones de Borges (1991) y De Cristóforis (2006) respecto a los patrones de locación espacial a fines del siglo XIX de portugueses y españoles en Buenos Aires, como también la expuesta por Mcgee Deutsch (2017) respecto a las múltiples experiencias culturales vividas por las mujeres judías en las habitaciones y pasillos de los conventillos de la misma ciudad.

Ahora bien, creemos que estos espacios y prácticas que configuraban la sociabilidad de estas comunidades, y que funcionaron como "refugios de etnicidad" donde encontraban "(..) certezas, continuidades, pero también formas de adaptarse, de reencontrarse, de replantear sus identificaciones en un ambiente que brindara seguridad, de legar y compartir con sus hijos una cultura que temían perder" (Seiguer, 2017, p.258), no pueden ser comprendidos como espacios alienados al contexto sociocultural imperante. Aquellas personas que se percibían como integrantes de un colectivo étnico no fueron (ni son) agentes externos ni excluidos de una dinámica mayor y transcultural que motorizaba préstamos, superposiciones y olvidos que inhibieron y/o posibilitaron la vida en la metrópolis porteña al mismo tiempo que, experiencias y narrativas comunes dentro de la propia comunidad. 
Para lograr una mayor aproximación a las experiencias y expectativas desde el análisis histórico de las colectividades en general y de sus protagonistas en particular, creemos pertinente poner el foco de atención en la interacción con el entorno social y político al que se encontraban integradas. En este sentido, el concepto de "zonas de contacto" adquiere importancia a la hora de dar cuenta de esos momentos y espacios donde las colectividades y sus significaciones étnicas "chocaron" y "negociaron" en las esferas publicas tanto con el Estado y la sociedad porteña como con otras colectividades, a pesar de su mayor o menor reticencia de sentirse parte de la sociedad que integraban. Del mismo modo, los denominados espacios étnicos pueden reconocerse como "espacios seguros", en tanto y en cuanto no solo funcionaron como continuadores de una cultura prexistente, sino también desarrollaron su dinámica a sabiendas de la interacción que establecieron con el contexto político y social en las que se encontraban establecidas.

\section{ZONAS DE CONTACTO Y ESPACIOS SEGUROS EN EL SISTEMA EDUCATIVO NACIONAL:}

Los años del aluvión inmigratorio acompañaron el proceso de consolidación de un Estado nacional fuerte y centralizado en lo militar, fiscal y administrativo, el cual se había iniciado décadas atrás tras el fin de las Guerras civiles (Sabato, 2012). Dentro de aquel entramado de disposiciones y planes que llevó adelante la gestión estatal se encuentra la denominada ley de Educación general de la Republica (Ley 1420), promulgada en 1884 durante el gobierno Julio Argentino Roca, cuyo "proyecto educativo fue parcialmente una respuesta a la creciente diversidad cultural y lingüística traída por los inmigrantes” (Bryce, 2019, p.112). La ley no solo estableció la laicidad de la educación, sino también la hegemonía de cualquier proyecto educativo a bajo el control Estatal:

Su objetivo explícito fue favorecer y dirigir el desarrollo "moral, intelectual y físico de todo niño de 6 a 14 años de edad", y para ello establecía el carácter gratuito y obligatorio de la educación pública, creaba el Consejo Nacional de Educación - cuyo primer titular fue Sarmiento-, formulaba el principio de la libertad de enseñanza y reglamentaba la existencia de escuelas particulares bajo fiscalización estatal (Sabato, 2012, p.323).

Esta serie de disposiciones, cuyo margen de aplicación inicial fueron los Territorios Nacionales y la Capital Federal, tuvieron una fuerte repercusión en las instituciones educativas de las comunidades étnicas, asentadas en su mayoría en la metrópolis porteña. Desde aquel momento, tuvieron que articular sus planes de estudio en torno al título y examen general de enseñanza primaria y, por ende, a los requerimientos establecidos por el Consejo Nacional de Educación (CNE), entre los que se destacaron la obligatoriedad de que parte del personal docente sea de origen argentino, así como una cantidad establecida de horas-clase en idioma español dependiendo el año lectivo.

Para Bryce (2019), las pautas impulsadas por los funcionarios de este organismo parecen haber estado ancladas ideológicamente bajo dos condiciones. Por un lado, la visión de una Argentina como unidad etnocultural que debía mantenerse o ser creada. Por otro, un ideal de nación sustentado en premisas europeas que establecían una correspondencia lineal entre el idioma (en este caso el español) y la etnicidad como elementos fundantes de la misma. Por ende, se inhibía cualquier reconocimiento de una identidad plural ligada al multilingüismo, al mismo tiempo que se estipulaba como imprescindible la escolarización para hacer de aquella Babel de idiomas que era la argentina, una única y cohesiva nación. La "cuestión nacional" se transformó en una serie de disposiciones en las cuales "el estado marcaba ya una definida línea de acción, imponía una liturgia patria escolar y civil con el objeto de transmitir los símbolos de la nacionalidad argentina" (Bjerg, 2009, p.404). La enseñanza de la historia y geografía nacional, así como el idioma español estipuladas en el Plan de estudio del CNE, funcionaron como una herramienta indispensable para "argentinizar" aquellos futuros ciudadanos mediante una revalorización de la cultura hispanoamericana (Bjerg, 2009; Bertoni \& Rock, 2001). Es decir, las clases dirigentes estimularon y "vieron la ciudadanía como una categoría cultural y lingüística, además de política” (Bryce, 2019, p.155). 
Sin embargo, la formalización de un proyecto educativo mediante disposiciones legales y el desarrollo de las actividades regulatorias del CNE no implicó una transformación inmediata del sistema educativo imperante en la práctica. La falta de presupuesto como de infraestructura, que llevo años suplir, implicaron que a pesar de que "entre 1882 y 1895 la población escolar de las escuelas italianas de Buenos Aires paso del 20\% al 5\% con respecto al total de niños que asistían a las escuelas públicas" (Bjerg, 2009, p.404), aún "en 1908, el 30\% de los 139.684 estudiantes de la ciudad asistían a escuelas católicas o privadas" (p.151). Bajo estas circunstancias, no es casual encontrar en los proyectos educativos de las colectividades étnicas cierto margen de acción que, cumpliendo las normativas establecidas, lograron aun así hacer pervivir sus objetivos iniciales (Cibotti, 2000). Por ejemplo, como bien ha expuesto Seiguer (2017), la colectividad inglesa ${ }^{4}$ en la Argentina desarrollo un entramado de instituciones educativas que permitieron, en conjunto con las instituciones anglicanas y distintos espacios de sociabilidad, el desarrollo de una narrativa que vinculaba mediante la reproducción de la lengua y las costumbres británicas a aquella pequeña comunidad con Gran Bretaña.

Es decir, aquellos espacios vacantes entre lo jurídico y lo real, donde los proyectos particulares de las comunidades étnicas y la normativa estatal entablaban disputas y negociaciones, pueden ser reconocidos en términos de Pratt (1991) como zonas de contacto. Estas se comprenden de una relación asimétrica entre el Estado Argentino y el conjunto de comunidades étnicas y sus instituciones, las cuales debieron comprometerse en el entramado de disposiciones y prácticas culturales legitimadas y/o establecidas por él, reduciéndose así sus márgenes de acción. Si el sistema educativo nacional de entre siglos pueden comprenderse como tal, las prácticas y mensajes que la comunidad educativa se proponía impulsar en las aulas de las escuelas bilingües pueden advertirse como experiencias acordes a un espacio seguro, donde sus protagonistas supieron analizar su contexto y desarrollar una definición propia de lo que significaba pertenecer a la nación argentina $y$, por ende, un sentido de ciudadanía alterna a los nacionalismos decimonónicos (Bryce, 2019; Seiguer, 2017). De modo tal que, y a sabiendas de lo planteado por Bryce (2019) respecto a las escuelas Bilingües porteñas, estas instituciones educativas cumplieron con las exigencias cívicas y lingüísticas impartidas por el Consejo Nacional de Educación y, simultáneamente, desarrollaron una propuesta propia donde aquellos elementos que los configuraban como colectivo no se perdían, sino que eran reivindicados para luego desarrollar con ellos una nueva propuesta de lo que significaba pertenecer a la nación argentina.

Por ejemplo, al momento de analizar cómo evaluaban los directores su rol en la formación de los jóvenes que visitaban hacia el año 1909 la Escuela Cangallo, una de las principales escuelas bilingües alemán-español del país, Bryce (2019) recupera de las memorias de la institución lo siguiente:

El objetivo principal de la escuela es mantener en los niños todo aquello que vemos como específicamente alemán. Sobre todo, nos esforzamos por mantener en los niños nuestro bello, fuerte y majestuoso idioma junto con el conocimiento y la actividad alemanas". (...) "No puede pasarse por alto el hecho de que los alumnos tienen derecho a exigir el conocimiento y las destrezas necesarias para su lucha para sobrevivir aquí. Dado que, salvo unas pocas excepciones todos los alumnos buscaran su subsistencia en este país, nuestros objetivos pedagógicos apuntan a satisfacer estas necesidades desde el principio (Bryce, 2019, p.121).

Al unísono, en otra nota del mismo documento se afirmaba que:

Es verdad que queremos hablarles a nuestros alumnos en el idioma de sus padres para que aquellos puedan expresarles sus sentimientos más íntimos a sus familias. Pero también es verdad que queremos que dominen con la misma perfección la rica y armoniosa lengua de Cervantes y de Lope de Vega para la vida cívica y patriota de los alumnos, como también para un futuro próspero (Bryce, 2019, p.122).

Bryce (2019) nos advierte que, simultáneamente, cuando se pronunciaba la irrenunciable misión de hacer que aquellos niños puedan hacer pervivir el entramado de costumbres y lazos que los unía con sus padres como alemanes (étnicos), se creía que uno de los objetivos principales de la institución se ubicaba en hacer de su educación no solo la herramienta esencial para prepararlos para su futuro en la Argentina, sino también, 
y principalmente, como el factor trascendental para el civismo y el patriotismo nacional de aquellos futuros ciudadanos porteños. En tanto, "desde el punto de vista de los educadores inmigrantes y de los padres, fomentar la integración cívica y el bilingüismo no debilitaba el proyecto de la ciudadanía de una educación primaria universal" (p.172).

En un sentido análogo, Seiguer (2017) se ha pronunciado en referencia a las English Schools en Argentina, las cuales como expresaba uno de sus referentes principales, no solo lidiaron con problemáticas y desafíos similares a las de cualquier Escuela Bilingüe:

Todo esto está contra nosotros: el espíritu nacionalista que se resiente contra los elementos extraños y desea absorber a todos
los niños de país, las leyes educativas que con toda razón insistieron en el idioma castellano y el patriotismo, el costo casi
prohibitivo de proveer edificios adecuados y de traer nuestros maestros desde el hogar, la escasez comparativa de escolares
que vuelve difícil asegurarse un numero lo suficientemente grande como para pagarlo (...) nuestra población constantemente
cambiante, y la conducta despreocupada de los padres, que quizá son más afectados por el ambiente de los que creen (Seiguer,
2017, p.216)

Sino también, rescataban (en sus propios términos) la inconfundible tarea que estaban llevando a cabo en salvaguardar a aquellos niños de perder su identidad étnica como futuros hombres del imperio británico al mismo tiempo que, se los educaba como futuros ciudadanos argentinos.

Se logra una medida apreciable de éxito (...) en su resultado total constituyen una buena fuerza hacia la preservación de la nacionalidad (...) ciertamente no tenemos razón alguna para avergonzarnos de ellos. Porque mientras son leales a las leyes de la Argentina, y obedecen las reglas del código nacional de educación y enseñan el idioma castellano de acuerdo con lo que les es requerido, representan sin embargo los ideales y la conducta británica de todas las maneras posibles (Seiguer, 2017, p.216)

Más allá de la promoción por parte de los adultos por hacer de sus niños parte de una comunidad imaginada (Anderson, 2006), debemos poner en consideración también las experiencias de los propios jóvenes, principalmente los recién arribados al país, quienes podían vivenciar episodios traumáticos en las escuelas públicas, tanto por profesar una religión distinta al catolicismo o simplemente ante las dificultades de expresarse en español en un momento donde, como hemos advertido, el hispanismo se configuraba como el elemento fundante de la tradición nacional argentina. Todos ejemplos de cómo el sistema educativo puede expresarse como zona de contacto entre culturas. Esto hacia aún más interesante la posibilidad de generar espacios donde ciertas prácticas culturales no solo eran reivindicas, sino también se establecían como los elementos configurantes para las colectividades.

Algunos estudiantes experimentaron el prejuicio. En la década de 1930, una maestra de escuela primaria les gritaba a sus alumnos asquenazíes y mantuvo a una niña encerrada en el sótano hasta que la encontró la madre. Otro profesor no creía que una estudiante fuera judía italiana: pensaba que era imposible ser ambas cosas. La falta de confianza en su palabra se agregaba al trauma del exilio: primero Italia la había degradado por ser judía; ahora, un argentino negaba sus orígenes. Los compañeros de clase daban por sentado que las niñas italianas eran católicas y les advertían que tuvieran cuidado en su trato con los rusos, como llamaban a todos los judíos. (McGee Deutsch, 2017, p. 97).

Al exponer estas situaciones, Mcgee Deutsch (2017) sostiene que, "el autoritarismo puede haber llevado a algunas niñas judías a asimilarse silenciosamente e incluso abandonar "muestras externas de que eran judíos" (p.98). Situación que, podemos imaginar, se repitió en no pocas ocasiones con niños de otros colectivos étnicos. Por otra parte, Mcgee Deutsch afirma que la red educativa judía, dinamizada por la Alianza Israelita Universal (AIU) y la Asociación de Colonizacion Judia (Jewish Colonization Association, JCA), expandió sus propuestas educativas iniciadas en las colonias agrícolas del país en las ciudades más importantes. De modo tal que "los institutos de las sinagogas y de las AIU-JCA hacían hincapié en las instrucciones religiosa, la historia judía y las lenguas Idish, española o árabe, según las características étnicas de la escuela” (p.99).

Otra experiencia a recuperar en la obra de Bryce (2019) se encuentra en la caracterización de estas instituciones como espacios donde las simbologías argentinas y alemanas se entremezclaban para generar una 
atmosfera "híbrida", donde las banderas de ambas naciones se entremezclan con estatuillas de los próceres nacionales y el Káiser Guillermo. Fotografías y memorias de distintos eventos en las instituciones aparecen como prueba de la celebración de costumbres nacionales, con vestimentas gauchescas o uniformes de la caballería argentina, en una seria preocupación por los actos patrios, al mismo tiempo que se realizaban también festivales donde se recuperaban ciertas tradiciones europeas.

Estos festivales eran una forma en que los padres y otros promotores escolares pudieran presentar los símbolos de Europa a una generación6y más joven y hacer que esta representara una narrativa del legado cultural. A través, de esta teatralidad se construían ideas e imágenes de la madre patria que los niños nunca habían visto y que sus padres recordaban de manera selectiva. (Bryce, 2019, p.141)

Es decir, los programas del CNE en las escuelas bilingües se cumplían y simultáneamente eran subvertidos en un nuevo estilo de narrativa escolar, donde la pluralidad lingüística y cultural no simbolizaba la deserción a las responsabilidades cívicas a la nación argentina. En todo caso, las instituciones educativas de las colectividades funcionaron como espacios seguros del mismo modo que las sociedades mutuales y los periódicos. Espacios simbólicos o materiales donde sus integrantes, como expondremos en el siguiente apartado para el caso de la colectividad alemana en el marco de la Gran Guerra, podían encontrarse y redefinir su lugar dentro de la esfera pública y del entramado de situaciones políticas y sociales que tenían lugar en Buenos Aires.

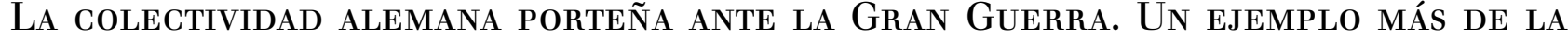 ZONA DE CONTACTO:}

Las colectividades étnicas asentadas en Buenos Aires durante la Gran Guerra tuvieron un gran protagonismo en la esfera pública nacional mediante colectas, programas de reclutamiento y distribución de propaganda bélica de un bando y otro (Tato, 2017; 2018). A pesar que el neutralismo defendido por el Gobierno nacional inhibió un recrudecimiento más allá de esporádicas trifulcas callejeras entre germanofilos y aliadófilos, la Gran Guerra significo para la colectividad alemana pugnar por el reconocimiento dentro de la elite nacional y la opinión pública que estaba en su mayoría familiarizada con la cultura francesa e inglesa tanto por razones históricas como lingüísticas. La colectividad desarrolló distintas estrategias para subvertir tal situación como, por ejemplo, el diario La Unión (1914-1919), publicado en español y cuyos objetivos fueron impugnar las noticias difamatorias y divulgar los argumentos alemanes al lector argentino (Hoffmann, 2009). Del mismo modo, los dos periódicos mas importantes de la colectividad, como ha afirmado Ismar (2005), "[w]ährend des Ersten Weltkrieges kam es zu einer in der Geschichte der Deutschen in Argentinien fast einmaligen Phase der Zusammenarbeit, in der selbst das Argentinische Tageblatt und die Deutsche La Plata Zeitung ihre von Konkurrenz und Missgunst geprägten Differenzen vergaße" (p.2).

Al respecto, Hoffmann (2009) y Bryce (2008) han propuesto que tanto los periódicos como las asociaciones sostuvieron una posición que remarcaba al Imperio Alemán no solo como la víctima en la confrontación que luchaba por conservar su honor y su reputación, sino también como un país amante de la paz con una misión civilizatoria para toda la humanidad. Mas, cuando tuvieron lugar tanto el "Incidente Luxburg" como los hundimientos de los navíos Toro (1917) y Monte Protegido (1917), entre otros, el clima político nacional dio un golpe de mano y parte de la opinión publica vio representado en las colectividades germanohablantes asentadas en la región al enemigo de la patria. Lo que se tradujo en la deslegitimación de colectividad y en la ampliación de las (ya existentes) "listas negras" de empresarios y trabajadores como en el saqueo y destrucción de negocios de la propia colectividad por parte de agrupaciones nacionalistas argentinas (Tato, 2017).

Ante esta situación, la colectividad alemana no solo se replegó en la seguridad de sus asociaciones y mutuales (Deutsche Wohltätigkeitsgesellschaft, Verein zum Schutze Germanischer Einwanderer, Deutscher 
Hospitalverein, Deutscher Volksbund für Argentinien) para contener las dificultades económicas que apesadumbraban a más de la mitad de la comunidad durante la contienda (despidos, desalojos y destrucción de negocios), sino también sentaron las bases de la futura Cámara de Industriay Comercio Argentino-Alemana (1924), que aglutinó a cientos de empresarios unidos ante las dificultades que enfrentaban para desarrollar sus negocios en el país tanto por los estrictos controles aduaneros, los embargos y rupturas de contratos de modo irregular (Newton, 1977). Además, se desarrollaron una serie publicaciones que buscaron resignificar la presencia germana en la región.

Desde septiembre de 1917 hasta 1918, el Deutsche La Plata Zeitung publicó una serie dominical sobre la historia de los alemanes en el Río de la Plata para mostrar el papel que éstos jugaron en el desarrollo de la cultura en los países de América de Sur. De este modo, trataron de darle un apoyo moral a la "comunidad alemana" en términos de superioridad (Hoffmann, 2009, p.129).

Mediante el diario La Unión, se involucraron en el debate entre rupturistas y neutralistas en el que se sumergió la Argentina ante el impacto de la guerra submarina y el ingreso de los Estados Unidos en la contienda, nítidamente a favor de los segundos (Tato, 2017). Durante fechas simbólicas para la nación argentina, también se publicaron panfletos que reafirmaban el compromiso de la colectividad alemana con la soberanía nacional:

Inglaterra impulsada por ese amor al respecto y a la libertad de la naciones débiles con que ha ido formado su inmenso imperio (...) entro a sangre y fuego en las Malvinas, asesinando cruelmente a los argentinos que las defendían, y arrió nuestra bandera para izar aquella a cuya sombra los filibusteros escribieron su negra historia (...) Mientras Inglaterra nos paga la injuria de retener las Malvinas, todo corazón sinceramente argentino debe considerar a Inglaterra como enemigo de su patria (volante anónimo citado en Tato, 2017, p.34).

En otras palabras, ante lo que podemos denominar las presiones sufridas en la zona de contacto, la colectividad se consolidó en sus "espacios seguros", desarrollando desde allí estrategias que buscaron replicar la inseguridad y discriminación que experimentaron en la metrópolis rioplatense y recomponer la legitimidad como aquel colectivo que, como ha propuesto Newton (1977), hasta el inicio de la conflagración eran altamente respectados en el círculo comercial y científico.

\section{Conclusión:}

A lo largo de este artículo se buscó argumentar y ejemplificar de qué modo la obra de Pratt (1991) puede comprenderse como una original herramienta conceptual dentro de los estudios históricos, capaz de dar cuenta tanto de la interacción entre culturas como de las estrategias que los sujetos pueden desarrollar para readaptarse en un dialogo intercultural que en ocasiones se establece de modo desigual. Para esto, por un lado, se analizó como entre el entramado de disposiciones y discursos provenientes del CNE y el accionar de la comunidad educativa en las escuelas bilingües se deslizo un vacío o espacio de oportunidades para la supervivencia de un discurso alternativo de ciudadanía (Seiguer, 2017; Bryce, 2019). Como ha desarrollado Bryce (2019), las escuelas Bilingües en Buenos Aires supieron crear una definición pluralista de la misma, donde aquel paradigma que asimilaba monolingüismo con etnicidad y nación se suplantaba por una visión que veía posible pertenecer a una comunidad étnica y al unísono ser un "buen" ciudadano de la nación en la que uno residía. Por otro lado, nos detuvimos a analizar como la colectividad alemana se replegó y desarrollo estrategias para subvertir tanto en el plano material como simbólico las penurias y difamaciones que estaba protagonizando a consecuencias de las repercusiones de la Primera Guerra Mundial en la región.

Planteamos considerar aquellos espacios étnicos de sociabilidad tanto simbólicos como materiales y, en particular, las aulas de las instituciones educativas bilingües y la producción, difusión y consumo de panfletos y periódicos en alemán y español, como estrategias propias de los espacios seguros, funcionales a subvertir la incomodidad de la zona de contacto en la que se había convertido el sistema educativo nacional tras 1884 
como la esfera pública porteña durante la Gran Guerra. Sin embargo, esta interpretación nos lleva a establecer también cierto margen de diferencia respecto a los postulados de Pratt (1991), quien observa en la dinámica del aula la reproducción de la zona de contacto que es el sistema educativo en general. En tanto, como bien hemos intentado ejemplificar mediante las obras de Seiguer (2017), Bryce (2019) y Mcgee Deutsch (2017), para el caso particular de las colectividades étnicas de fines del siglo XIX y principios del XX tanto las instituciones educativas bilingües como la dinámica de los cursos en los espacios étnicos como las sinagogas funcionaron como espacios seguros desde los cuales no solo los padres, profesores y alumnos reproducían su compromiso y pertenencia a su comunidad, sino también una plataforma desde donde resignificaban su participación en la sociedad que integraban.

\section{REFERENCIAS}

Anderson, B. (2006) Comunidades imaginadas. Reflexiones sobre el origen y difusión del nacionalismo. México D.F: Fondo de cultura económica.

Anzaldúa,G. (1999) Borderlands/La frontera: the new mestiza. San Francisco: Aunt Lute Books.

Baily, S. L. (1978). The role of two newspapers in the assimilation of Italians in Buenos Aires and Sao Paulo, 18931913. International Migration Review, 12(3), 321-340.

Baily, S., \& Scarli, A. (1982). Las sociedades de ayuda mutua y el desarrollo de una comunidad italiana en Buenos Aires, 1858-1918. Desarrollo Económico, 21(84), 485-514. https://doi.org/10.2307/3466611

Bertoni, L. A., \& Rock, D. (2001). Patriotas, cosmopolitas y nacionalistas. La construcción de la nacionalidad argentina a fines del siglo XIX. Buenos Aires: FCE.

Bjerg, M. (2009). Historias de la Inmigración en la Argentina. Buenos Aires: Edhasa,

Bindernagel, F. (2018). Deutschsprachige Migranten in Buenos Aires: Geteilte Erinnerungen und umkämpfte Geschichtsbilder 1910-1932. Paderborn: Verlag Ferdinand Schöningh.

Borges, M. (1991). Características residenciales de los inmigrantes portugueses en Buenos Aires en la segunda mitad del siglo XIX. Estudios migratorios latinoamericanos, 6(18), 353-382.

Brubaker, R. (2005). The 'diaspora' diaspora. Ethnic and racial studies, 28(1), 1-19. https://doi.org/10.1080/01419 87042000289997

Bryce, B. (2008). Germans in Ontario and Buenos Aires, 1905-1918: Das Argentinische Tageblatt and Das Berliner Journal's Discourse about Ethnicity and Its Changes During World War I. Toronto: York University.

Bryce, B. (2019). Ser de Buenos Aires: alemanes, argentinos y el surgimiento de una sociedad plural 1880-1930. Buenos Aires: Editorial Biblos.

Cagiao Vila, P. (2002). Los gallegos en Buenos Aires a través de la prensa de la colectividad (1925-1930). En III Congreso Internacional de Historiadores Latinoamericanistas. Santiago de Compostela: Universidad de Vigo.

Canagarajah, A. (1997). Safe Houses in the Contact Zone: Coping Strategies of African-American Students in the Academy. College Composition and Communication, 48(2), 173-196. https://doi.org/10.2307/358665

Cibotti, E. (1994) Periodismo político y política periodística; la construcción pública de una opinión italiana en el Buenos Aires finisecular. Entrepasados, 7, 7-26. Recuperado de https://ahira.com.ar/

Cibotti, E. (2000). Del habitante al ciudadano: la condición del inmigrante. En Lobato M \& Suriano, j (Comps). Nueva Historia Argentina. El progreso, la modernización y sus limites (1880-1916) (pp. 365-409). Buenos Aires: Editorial Sudamericana.

Cólera, C. J. (2008). El valle medio del Ebro como zona de contacto lingüístico de las lenguas paleohispánicas. Revista española de Lingüistica, 38(1), 5-32.

D'Amore, A. M. (2010). Traducción en la zona de contacto. Mutatis Mutandis: Revista Latinoamericana de Traducción, 3(1), 30-44.Recuperado de https://revistas.udea.edu.co/index.php/mutatismutandis/article/view/ 5183ace 
Da Orden, M. L. (2020). Salud, inmigración y ayuda mutua en Argentina: el Centro Gallego de Buenos Aires entre la crisis y la emergencia de un nuevo sistema sanitario (1930-1950). Revista de Indias, 80(280), 847-880. https ://doi.org/10.3989/revindias.2020.024

De cristóforis, N. A. (2006). Buenos Aires como destino de la emigración gallega y asturiana: los procesos de integración a mediados del siglo XIX. Anuario del Centro de Estudios Históricos "Prof. Carlos SA Segreti", 6(6), 20-46. Recuperado de https://revistas.unc.edu.ar/index.php/anuarioceh

De Cristóforis, N. A. (2016). El Centro Gallego de Buenos Aires frente a la comunidad inmigrada, la política española y el Estado argentino: crisis y oportunidades de expansión del modelo mutualista. RiMe. Rivista dell'Istituto di Storia dell'Europa Mediterranea, 17(1) 87-105. https://doi.org/10.7410/1209

Dujovne, A. (2014). Una historia del libro judio: La cultura judía argentina a través de sus editores, libreros, traductores, imprentas y bibliotecas. Buenos Aires: Siglo XXI Editores.

Devoto, F. (1987) Participación y conflictos en las sociedades italianos de socorros mutuos. En F. Devoto y R, Gianfausto (comps.), La inmigración italiana en la Argentina. Buenos Aires: Biblos.

Devoto, F., \& Benencia, R. (2003). Historia de la inmigración en la Argentina. Buenos Aires: Sudamericana.

Deutsch, S. M. (2017). Cruzar fronteras, reclamar una nación: historia de las mujeres judias argentinas, 1880-1955. Buenos Aires: FCE.

Dore, G. (1985). Un periódico italiano en Buenos Aires (1911-1913). En F Devoto, G Rosoli (Comps) La inmigración italiana en la Argentina (pp.127-140). Buenos Aires: Biblios

Elmborg, J. (2006). Libraries in the Contact Zone: On the Creation of Educational Space. Reference \& User Services Quarterly, 46(1), 56-64. https://doi.org/10.5860/rusq.46n1.56

Fernandez, A. (1987). El mutualismo español en Buenos Aires, 1890-1920. Un estudio de caso. Cuadernos de Historia Regional, 3(8), 36-71.

Fernandez. S (2001). Asociacionismo gallego en Buenos Aires (1936-1960). En Seixas, X. (Comp). La Galicia austral: la inmigración gallega en la Argentina (pp. 181-202). Buenos Aires Biblos.

Garabedian, M. H. (2012). " El correo español" de Buenos Aires y la prensa española en el Río de la Plata. Nuevos enfoques para su estudio. Historia. Questoes \& debates, (56), 160-177.

Golluscio, L. A., \& Dreidemie, P. (2017). La lengua como "zona de contacto": una introducción. Signo y seña, (17), 11-17. https://doi.org/10.34096/sys.n17.5724

Gruss, V. (2017). Le Courrier de La Plata, Diario de la colectividad francesa rio-platense. Temas de Historia Argentina y americana, (8), 95-141. Recuperado de https://anaforas.fic.edu.uy/jspui/bitstream/123456789/36902/1/Ot eizaLeCourrier.pdf

Harris, J. (1995). Negotiating the contact zone. Journal of Basic Writing, 14(1), 127-142. Recuperado de https://wa c.colostate.edu/jbw/v14n1/

Hoffmann, K. (2009). ¿Construyendo una "comunidad"? Theodor Alemann y Hermann Tjarks como voceros de la prensa germanoparlante en Buenos Aires, 1914-1918. Iberoamericana, 9(33), 121-137. Recuperado de http://r evista-iberoamericana.pitt.edu/ojs/index.php/Iberoamericana

Ismar, G (01.10.2005). Der deutsch-argentinische Pressestreit. Argentinisches Tageblatt, 1-8. Recuperado de http://w ww.tageblatt.com.ar/archivo/2005/10/Pressestreit.pdf

Lobato, M. Z. (2001). La Patria degli Italiani and Social Conflict in Early-Twentieth Century Argentina. En D. Gabaccia y F. Otanelli (Coord). Italian Workes of the World. Labor Migration and the Formation of Multhietnic States (pp. 127-140). University of Illinois Press, Urbana and Chicago.

Lu, M. (1994). Professing Multiculturalism: The Politics of Style in the Contact Zone. College Composition and Communication, 45(4), 442-458. https://doi.org/10.2307/358759

Mangold, F. (2017) Las Sociedades de Socorros Mutuos en la localidad de Las Rosas durante el siglo XIX y primeras décadas del siglo XX. Historia Regional. 3(37). 101-127. Recuperado de http://historiaregional.org/ojs/index. $\mathrm{php} /$ historiaregional/index 
Merry, E. S. (1998). Law, culture, and cultural appropriation. Yale JL \& Human., 10, 575-603. Recuperado de: http s://digitalcommons.law.yale.edu/yjlh/vol10/iss2/16

Schirp, K. E. (2001). Die Wochenzeitung" Semanario Israelita": Sprachrohr der deutsch-jüdischen Emigranten in Argentinien. Münster: LIT Verlag

Meding, H. M. (1995). Nationalsozialismus und Argentinien: Beziehungen, Einflüsse und Nachwirkungen. Frankfurt: Lang.

Newton, R. C. (1977). German Buenos Aires, 1900-1933: Social Change and Cultural Crisis. Austin: University of Texas Press.

Otero, H. (2010). El asociacionismo francés en la Argentina. Una perspectiva secular. Estudios Interdisciplinarios de América latina y el Caribe, 21(2), 123-152.

Otero, G (2011) Las escuelas étnicas de la comunidad francesa. El caso argentino, 1880-1950. Anuario de Estudios Americanos, 68(1). http://doi.org/10.3989/aeamer.2011.v68.i1.536

Pomerantz, A., \& Bell, N. D. (2011). Humor as safe house in the foreign language classroom. The modern language journal, 95(1) 148-161. https://doi.org/10.1111/j.1540-4781.2011.01274.x

Pratt, M. L. (1991). Arts of the contact zone. Profession, 91, 33-40. Recuperado de http://www.jstor.org/stable/25 595469

Sebastiani, M. A. G. (2004). Crear identidades y proyectar políticas de España en la Argentin en tiempos de transformación del liberalismo. El diario Español de Buenos Aires (1905-1912). Estudios Migratorios Latinoamericanos, 18(55), 525-554.

Sabato, H. (2012). Historia de la Argentina, 1852-1890. Buenos Aires: Siglo XXI Editores.

Seiguer, P. (2017). Jamás he estado en casa: la Iglesia Anglicana y los ingleses en la Argentina. Buenos Aires: Editorial Biblos.

Tato, M. I. (2018). La batalla por la opinión pública: el diario argentino La Unión durante la Gran Guerra. En Compagnon, O; Foulard C; Martin, G \& Tato, M, I (coord.). América Latina. Una historia conectada (pp.307-320) México: Centro de Estudios Mexicanos y Centroamericanos.

Tato, M. I. (2017). La trinchera austral. La sociedad argentina ante la Primera Guerra Mundial. Rosario: Prohistoria.

Torry, E (2011). El asociacionismo vasco en Argentina. Notas sobre sus componentes identitarios. IX Jornadas de Sociología. Facultad de Ciencias Sociales, Universidad de Buenos Aires, Buenos Aires. Recuperado de https:// www.aacademica.org/000-034/623

Watkins, E. (2003). The art of the safe house. Recuperado de https://depts.washington.edu/egonline/wordpress/wpc ontent/uploads/2010/06/03.EWatkins.pdf

\section{Notas}

1 Algunos conceptos validos dentro de la historiografía nacional en este sentido son: "comunidades abiertas" de Cibotti (1990) como "Refugios de etnicidad" de Seiguer (2012).

2 Es importante aclarar que Bjerg (2009) al referirse aquí a "turcos" y "rusos" está dando cuenta de aquellos migrantes provenientes de los territorios pertenecientes a los ya disueltos Imperios otomano y ruso respectivamente. Estos mismos conceptos refieren a su uso coloquial en la Argentina para referirse a los migrantes provenientes del cercano oriente como de Europa oriental.

3 Ante la polisemia del concepto de diáspora, coincidimos con Brubaker (2005) en comprender que las comunidades diasporitas pueden reconocerse en base a tres criterios: 1) la dispersión forzada y/o traumática sobre un espacio que puede ser dentro como fuera de un Estado-nación; 2) la orientación hacia la patria. Es decir, la orientación real o imaginada hacia la patria como fuente legitima de la memoria colectiva del grupo; y 3) la pervivencia de limites culturales que permiten la preservación de ciertos lealtades y valores que las distinguen de la sociedad receptora.

$4 \mathrm{Al}$ igual que Bjerg (2009) respecto a los denominados "turcos" y "rusos", Seiguer (2012) reconoce la labilidad de los conceptos inglés, británico y anglohablante en las propias denominaciones que la comunidad británica utilizaba al momento de autodefinirse. Asimismo, el concepto "ingles" refiere también al uso coloquial utilizando en la Argentina para mencionarse a los arribados desde Gran Bretaña. 